\title{
Training volume and injury incidence in a professional rugby union team
}

\author{
Wayne Viljoen (PhD, CSCS) ${ }^{1}$ \\ Colleen J Saunders (BSc (Med) Hons (Exercise Science)) ${ }^{2}$ \\ Greg D Hechter (BA Hons (Biokinetics)) ${ }^{3}$ \\ Kerith D Aginsky (PhD) ${ }^{2}$ \\ Helen B Millson (MPhil (Sports Physiotherapy)) \\ ${ }^{1}$ SA Rugby (Pty) Ltd, Cape Town \\ ${ }^{2}$ UCT/MRC Research Unit for Exercise Science and Sport Medicine, Department of Human Biology, University of Cape Town \\ ${ }^{3}$ Western Province Rugby (Pty) Ltd, Cape Town
}

\begin{abstract}
Objective. To describe the incidence of injuries in a professional rugby team, and to identify any associations between injury rates and training volume.

Methods. This retrospective, descriptive study included all injuries diagnosed as grade 1 and above in a South African Super 12 rugby team. Injury incidence and injury rates were calculated and compared with training volume and hours of match play.

Results. Thirty-eight male rugby players were injured during the study period. The total number of annual injuries decreased from 50 (2002) to 38 (2004) $\left(\chi^{2}=0.84, p=0.36\right)$. The number of new injuries showed a similar trend $\left(\chi^{2}=2.81, p=0.09\right)$, while the number of recurring injuries increased over the 3 -year period. There was a tendency for total in-season injury rates to decrease over the 3 years $\left(\chi^{2}=2.89, p=0.09\right)$. The pre-season injury rate increased significantly over the 3 years $\left(\chi^{2}=12.7, p<0.01\right)$, coupled with a reduction in training exposure over the pre-season phase.

Conclusions. One has to be cognisant of the balance between performance improvement and injury risk when designing training programmes for elite rugby players. Although the reduction in training volume was associated with a slight reduction in the number of acute injuries and in-season injury rates over the three seasons, the performance of the team changed from 3rd to 7 th (2002 and 2004, respectively). Further studies are required to determine the optimal training necessary to improve rugby performance while reducing injury rates.
\end{abstract}

\section{CORRESPONDENCE:}

Dr Wayne Viljoen

Manager

BokSmart National Rugby Safety Programme, SA Rugby (Pty) Ltd PO Box 99

Newlands 7725

Tel: +2721-659 6732

E-mail: waynev@sarugby.co.za

\section{Introduction}

Rugby union is a team sport involving contact and collision of players running at fast speeds, ${ }^{1}$ and consequently has a high injury rate. ${ }^{2}$ Since the advent of professionalism in rugby union in October $1995^{3-5}$ professional players have become full-time athletes, with a greater emphasis on training for strength, speed and stamina, ${ }^{6}$ increase in size, ${ }^{5,7}$ speed and power, ${ }^{4,5}$ and improvement in rugby skills. ${ }^{3}$ Professional rugby players sustain considerably more injuries than amateur players, ${ }^{3,6,8}$ probably as a result of the greater size of the players, the faster pace at which the game is played, and the greater impact forces associated with these changes. ${ }^{3,9,10}$

The Super 14 (previously the Super 12) is a popular professional rugby tournament between regional sides from South Africa, New Zealand and Australia. Since the inception of this tournament, professional rugby union players have played significantly more rugby matches each year. Many elite South African players, who also play in national provincial tournament and international matches, may participate in as many as 35 matches in one season.

The multiplicity of factors that contribute to injury in rugby union makes it difficult to identify causality. ${ }^{9}$ However, to adequately condition players, reduce their risk of injury, and treat and rehabilitate rugby injuries appropriately, it is important to gain a better understanding of the nature and causes of rugby injuries, in particular their association with training. ${ }^{2}$ Therefore, the purpose of this study was to describe the incidence of injuries in a professional South African Super 12 rugby team over 3 years (2002 - 2004), and to identify any associations between injury rates and the mode and volume of training.

\section{Methods}

\section{Participants}

During the off-season 40 contracted players were selected to form part of the Super 12 rugby union training squad. Twenty-two of the initial 40 players were forwards, and 18 were backline players. In February, the number of contracted players was reduced to 28 (15 forwards and 13 backline players). The injured players in this study $(N=38)$ were all male $(26 \pm 2$ years of age). In accordance with similar research, ${ }^{11}$ and due to the nature of the professional game, the individuals who comprised the squad varied over the 3 years. Ten 
of these players were also part of the South African national squad. Informed consent was obtained by the union, and the Ethics Committee of the University of Cape Town approved this study.

\section{Preparation for the Super 12 tournament}

The off-season training cycle extended from mid-November to midDecember every year. Players then had an active rest period until the first week in January, when pre-season training began. The preseason training period entailed formalised strength and conditioning sessions, rugby training, training camps, unofficial 'friendly' matches $(N=3,2002 ; N=3,2003 ; N=2,2004)$, and specific individualised preparation.

The Super 12 tournament consisted of 5, 3 and 4 regional teams from New Zealand, Australia and South Africa, respectively, began in mid-February, and continued until mid-May. The number of matches varied depending on how well the team fared in the tournament $(N=12,2002 ; N=11,2003 ; N=11,2004)$. Players had approximately 2 weeks off at the end of the tournament and then participated in the national provincial tournament and/or in international test matches. Off-season musculoskeletal evaluations and medical screening assessments by the physiotherapist and the team sports physician precluded any previously diagnosed injuries and injuries sustained during other tournaments from being carried over to the analysis of the current study.

\section{Data collection}

Data were collected under the guidance of the same team physiotherapist and strength and conditioning trainer for the duration of the study. All injuries requiring medical attention, ${ }^{12,13}$ diagnosed as grade 1 or above, were documented either directly after or within 5 days of the injury occurring, regardless of whether or not the injury resulted in the player missing training or not playing in a match. ${ }^{11} \mathrm{~A}$ grade 1 injury was defined as one in which there was pain, with minimal loss of muscle function or strength. ${ }^{14}$ We are cognisant of the consensus document on injury definitions published in $2007 .^{12}$ However, as our study was conducted before the consensus paper was published, the definition of injuries in our study was slightly different. An examination of the consensus definition suggests that the definition used in this study may slightly over-estimate the occurrence of an injury compared with the consensus definition.

\section{Injury rates}

Injury rates were determined using previously described methods and expressed as the number of injuries sustained per 1000 hours at risk. ${ }^{2,11-13,15-17}$ Match injury rates were calculated on the premise that there were only 15 player positions on the field, ${ }^{18}$ regardless of any substitutions made during the game. Match injury rates were computed under the assumption that rugby union matches last on average 80 minutes ( 1.33 hours) per game. ${ }^{9,11,18,19}$ Training injury rates were reported as a function of total training exposure time. ${ }^{13}$

- Match injury exposure (MIE) was determined by the number of games played during the specified seasonal cycle:

MIE = hours of play (1.33) $\times$ no. of players on the field (15) $\times$ no. of matches played.

- Match injury rates were then calculated:

Match injury rates $=$ (no. of injuries during matches/MIE) $x$ 1000.

- Training injury exposure (TIE) was determined in a similar way:

$\mathrm{TIE}=$ hours of supervised training $\mathrm{x}$ no. of contracted players (either 40 or 28 ).

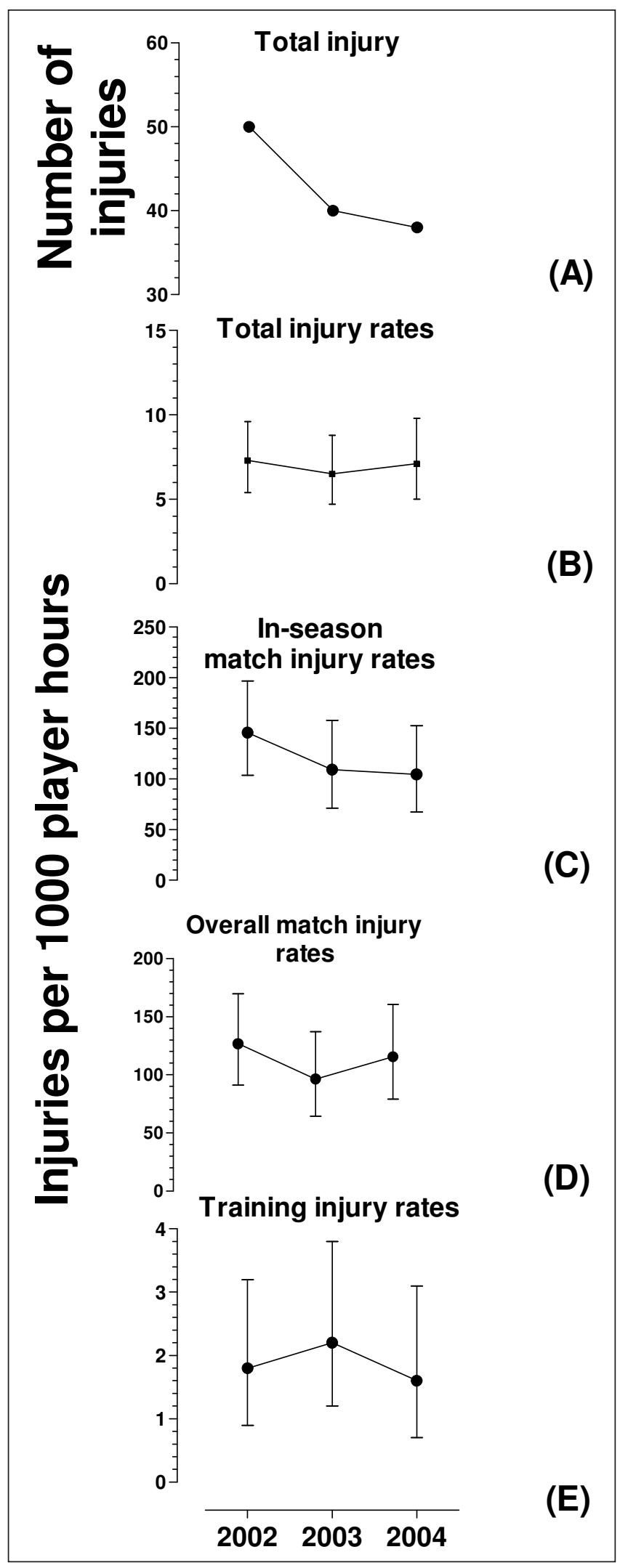

Fig. 1. The total number of injuries and injury rates incurred over a 3-year time period in a Super 12 Rugby Union team. (A) Total number of injuries incurred over the 3 years; (B) total injury rates over the 3 years, combining match and training injury rates; (C) in-season match injury rates; (D) overall match injury rates combining pre- and in-season rates; (E) training injury rates over the 3 years. 


\begin{tabular}{llll}
$\begin{array}{l}\text { TABLE I. Number of injuries } \\
\text { time spent on training (hours) }\end{array}$ & $\begin{array}{c}\text { suined and overall } \\
\text { from }\end{array}$ & $\mathbf{2 0 0 2}$ to & $\mathbf{2 0 0 4}$ \\
\hline & $\mathbf{2 0 0 2}$ & $\mathbf{2 0 0 3}$ & $\mathbf{2 0 0 4}$ \\
Number of injured players & 19 & 22 & 21 \\
Recurrent injuries & 12 & 10 & 18 \\
New injuries & 38 & 30 & 20 \\
Total injuries & 50 & 40 & 38 \\
Off-season training (h) & 32.7 & 28.1 & 30.7 \\
Pre-season training (h) & 56.2 & 63.8 & 40.5 \\
Combined off- and pre & 88.8 & 91.8 & 71.2 \\
-season training (h) & & & \\
In-season training (h) & 107.7 & 78.6 & 79.9 \\
Overall training time (h) & 196.5 & 170.4 & 151.1 \\
\hline
\end{tabular}

\section{Results}

\section{Injury incidence}

Table I and Fig. 1A show that the total number of injuries incurred per year decreased gradually, but not significantly, from 50 (2002) to $\left.38(2004) \chi^{2}=0.84, p=0.36\right)$. The number of new injuries showed a similar trend, decreasing from $38(2002)$ to 20 (2004) $\left(\chi^{2}=2.81\right.$, $p=0.09)$. When these values were normalised to the number of injured players, a similar pattern was found: 2.60 (2002), 1.82 (2003), and 1.80 (2004) injuries per injured player. The number of recurring injuries increased over the 3-year period from 12 (2002) and 10 (2003) to 18 (2004). Although this increase was not statistically significant $\left(\chi^{2}=0.63, p=0.43\right)$, it is clinically relevant as it is known that recurrent injuries are frequently under-reported within a season by nature of their definition. ${ }^{13}$

\section{TABLE II. Training injury exposure and injury rates within a Super 12 rugby team over a 3-year period}

\begin{tabular}{|c|c|c|c|c|c|c|c|c|c|c|}
\hline \multirow{2}{*}{\multicolumn{2}{|c|}{ Seasonal cycle }} & \multicolumn{5}{|c|}{ Match injuries } & \multirow{3}{*}{$\begin{array}{l}\text { TIE (h) } \\
3540\end{array}$} & \multirow{3}{*}{$\begin{array}{c}\text { Hours of training } \\
\text { per match } \\
29.5\end{array}$} & \multirow{2}{*}{\multicolumn{2}{|c|}{$\begin{array}{l}\text { Total IR } \\
(95 \% \mathrm{Cl})\end{array}$}} \\
\hline & & \multirow{2}{*}{$\begin{array}{l}\text { MIE (h) } \\
60\end{array}$} & \multicolumn{2}{|c|}{ No. of injuries } & \multicolumn{2}{|c|}{ Match IR $(95 \% \mathrm{Cl})$} & & & & \\
\hline \multirow[t]{2}{*}{2002} & Pre & & 3 & \multirow{2}{*}{38} & $\begin{array}{c}50 \\
(10.4-139.2)\end{array}$ & 126.7 & & & $\begin{array}{c}0.8 \\
(0.2-2.4)\end{array}$ & \multirow{2}{*}{$\begin{array}{c}7.3 \\
(5.4-9.6)\end{array}$} \\
\hline & In & 240 & 35 & & $\begin{array}{c}145.8 \\
(103.7-196.9)\end{array}$ & $(91.2$ - 169.7) & 3015 & 9.0 & $\begin{array}{c}14.4 \\
(10.6-19.2)\end{array}$ & \\
\hline \multirow[t]{2}{*}{2003} & Pre & 60 & 3 & \multirow{2}{*}{27} & $\begin{array}{c}50 \\
(10.4-139.2)\end{array}$ & \multirow{2}{*}{$\begin{array}{c}96.4 \\
(64.5-137.2)\end{array}$} & 3671 & 30.6 & $\begin{array}{c}2.4 \\
(1.1-4.6)\end{array}$ & \multirow{2}{*}{$\begin{array}{c}6.5 \\
(4.7-8.8)\end{array}$} \\
\hline & In & 220 & 24 & & $\begin{array}{c}109.1 \\
(71.2-158)\end{array}$ & & 2200 & 7.1 & $\begin{array}{c}12.8 \\
(8.7-18.1)\end{array}$ & \\
\hline \multirow[t]{2}{*}{2004} & Pre & 40 & 7 & \multirow{2}{*}{30} & $\begin{array}{c}175 \\
(73.4-327.8)\end{array}$ & \multirow{2}{*}{$\begin{array}{c}115.4 \\
(79.2-160.6)\end{array}$} & 2847 & 35.6 & $\begin{array}{c}4.2 \\
(2.1-7.3)\end{array}$ & \multirow{2}{*}{$\begin{array}{c}7.1 \\
(5.0-9.8)\end{array}$} \\
\hline & In & 220 & 23 & & $\begin{array}{l}104.5 \\
(67.4-152.7)\end{array}$ & & 2238 & 7.3 & $\begin{array}{c}10.6 \\
(6.9-15.5)\end{array}$ & \\
\hline
\end{tabular}

$\mathrm{MIE}=$ match injury exposure; $\mathrm{TIE}=$ training injury exposure

All injury rates (IR) are represented as the number of injuries incurred per 1000 hours of player exposure, and the $95 \%$ confidence intervals (Cls) are represented in parentheses. For this table, the pre-season represents both the off- and pre-season time periods.

- Training injury rates were then calculated:

Training injury rates $=$ (no. of injuries during training $/ \mathrm{TIE}) \mathrm{x}$ 1000.

- Subsequently total injury rate was determined as the number of injuries sustained in a seasonal cycle:

Total injury rates $=($ no. of injuries sustained $/(\mathrm{MIE}+\mathrm{TIE})) \times 1000$.

These were determined for both pre-season and in-season periods.

\section{Statistical analysis}

Basic descriptive statistics were used to explain the accumulated injury and training data over the 3 years. The $95 \%$ confidence intervals (Cls) for the injury incidence data were calculated using an exact binomial distribution. Differences in the incidence of injuries between categories for the three seasons were assessed using a chi-square analysis for trend $\left(\chi^{2}\right)$. Additionally, year-by-year comparisons between data were done using a $2 \times 2$ contingency table chi-square analysis applying Yates' continuity correction. Statistical significance was accepted when $p<0.05$.
Table II and Figs 1 and 2 specify the overall training exposure and injury rates within the Super 12 team over the 3 years. Table II shows that the number of match injuries sustained during the Super 12 season decreased from 38 (2002) to 27 (2003) and 30 (2004). While there was a tendency for a reduction in in-season match injury rates $\left(\chi^{2}=3.44, p=0.06\right)$, the overall match injury rates remained relatively unchanged over the 3 years $\left(\chi^{2}=0.31, p=0.58\right)$. In the pre-season phase, Table II shows an increase in the number of hours trained per match over the 3 years. However, this may be misleading because in 2004 the team played one less pre-season 'friendly' match. If they had played the same number of pre-season 'friendly' matches in 2004, the training hours per match would have been 23.7 instead of 35.6. Table II also shows a meaningful reduction in training per match during the competition season in 2003 (9.0 v. 7.1 v. 7.3 hours per match $-2002,2003,2004$, respectively), coupled with a tendency for the total in-season injury rates to decrease over the 3 years $\left(\chi^{2}=2.89\right.$, $p=0.09$ ). The pre-season injury rate, however, increased significantly over the 3 years $\left(\chi^{2}=12.7, p<0.01\right)$, and was coupled with a reduction in TIE over the pre-season phase - 3540 (2002), 3671 (2003) and 2 847 (2004) player exposure hours. The total injury rates, as with the abovementioned overall match injury rates over the entire training 


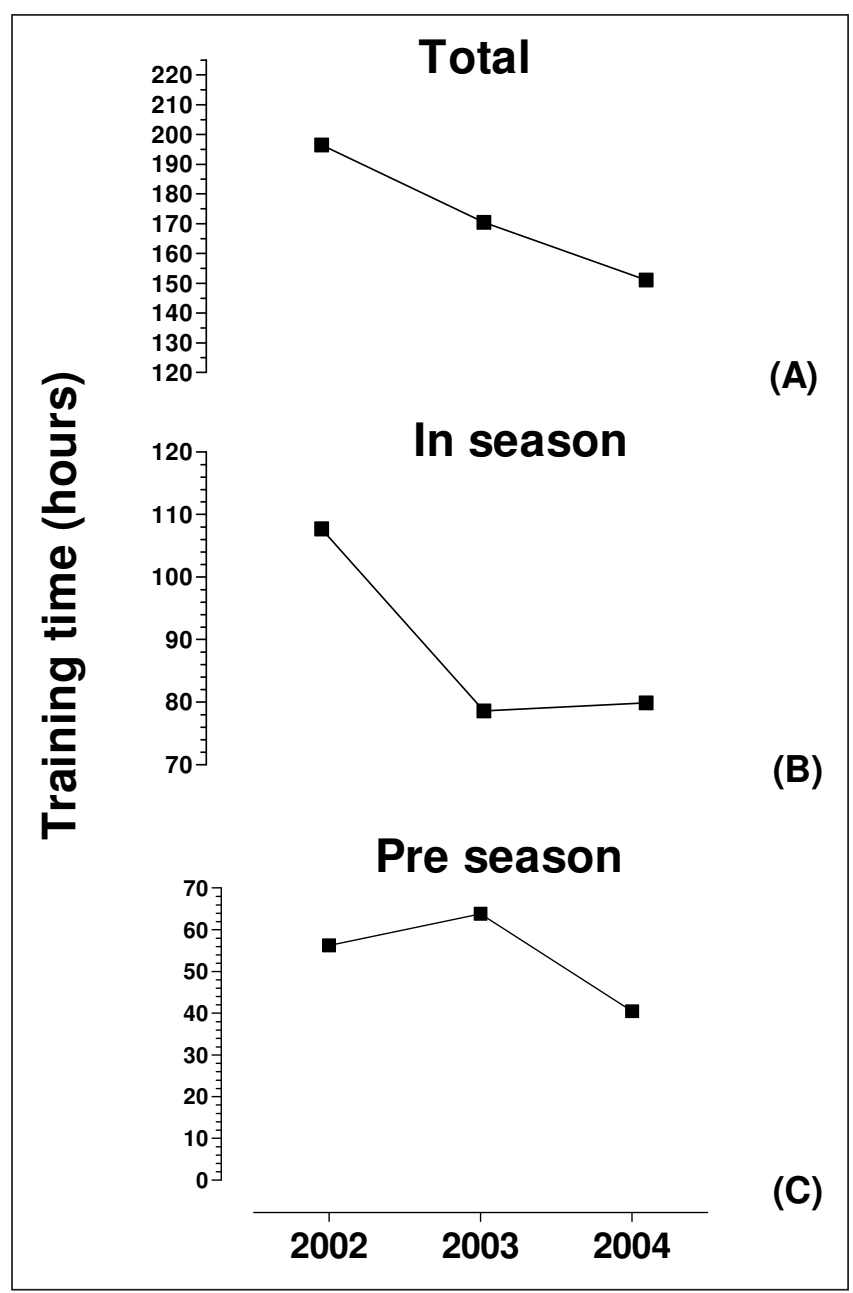

Fig. 2. Training volumes over the 3-year period studied. (A) Total training volumes over the 3-year period expressed in hours, combining off-, pre- and in-season training; (B) total in-season training volumes; $(C)$ total pre-season training volumes.

season (off-, pre- and in-season), remained similar over the 3 years $\left(\chi^{2}=0.01, p=0.90\right)$.

\section{Training analysis over the 3 years}

Seventy-four per cent of all injuries sustained over the 3 years occurred in a rugby match while $21 \%$ were related to rugby practice. Very few injuries were related to gym, rugby fitness conditioning or other causes. It is however prudent for the development of appropriate injury prevention strategies in rugby union to analyse the training patterns utilised in this study, as much more time is spent training for rugby than playing rugby. ${ }^{15}$

Table I shows the breakdown of time spent within the various training cycles over the 3 years. Off-season training time remained similar. However, it is evident that pre-season training volume increased slightly in 2003 (56.2 - 63.8 hours), and then decreased by $37 \%$ in 2004 to 40.5 hours (Fig. 2C). Although not significant $\left(\chi^{2}=2.14, p=0.14\right)$, this reduction has practical importance and is reflected in the combined preparatory training cycle (91.8 - 71.2 hours) $\left(\chi^{2}=1.12, p=0.29\right)$. A noticeable $27 \%$ decrease in in-season training volume $\left(\chi^{2}=1.97, p=0.16\right)$ was observed between 2002 and 2003 (Fig. 2B) and this reduction was maintained in 2004. If one compares the overall time spent on training, it is clear (Fig. 2A) that there was a noticeable trend towards a reduction in training volume over the 3 years $\left(\chi^{2}=3.06, p=0.08\right)$.
Table III shows the breakdown of the training data collected over the 3 -year study period. Rugby conditioning or fitness training contributed to $8 \%$ of the total training time over the 3 years and formed $23 \%$, $12 \%$ and $2 \%$ of the off-, pre- and in-season phases, respectively. Conditioning was defined as any form of rugby fitness training such as anaerobic intervals, aerobic training, fuel mix conditioning, and speed and agility training, ${ }^{15,16}$ and played a larger role in the off- and pre-season than during the in-season. Gym training formed $23 \%$ of the total training time, and contributed to $35 \%, 19 \%$ and $21 \%$ of the off-, pre- and in-season phases, respectively. The time spent on gym training in the pre-season phase was reduced over the 3 years (2002: 26\%; 2003: 16\%; 2004: 14\%). Rugby training sessions were defined as including structured game phase plays, skills training, kicking sessions, split sessions, defensive sessions, line outs, scrummaging, rucks, mauls and match training, ${ }^{15,16}$ and formed $53 \%$ of the total training time contributing to $36 \%, 49 \%$, and $62 \%$ of the off-, pre- and in-season training phases, respectively. The amount of time spent on rugby training during the in-season was also reduced over the 3 years (2002: 67\%; 2003: 61\%; 2004: 59\%). The Eco-challenge, a 24-hour endurance event during a training camp, was included in this analysis as it contributed to a large amount of TIE during 2003. Training injury rates (Fig. 1E) accounted for 1.9 injuries/1 000 player training hours over the 3 years studied (2002: 1.8 (95\% Cl: 0.9 - 3.2); 2003: 2.2 (95\% Cl: 1.2 - 3.8); 2004: 1.6 (95\% Cl: 0.7 - 3.1)).

\section{Discussion}

\section{Injury incidence}

The first finding from this study was that the number of total injuries (Fig. 1A) and number of new injuries (Table I), albeit not significant, gradually decreased over the 3 years. However, when comparing the total (Fig. 1B) and match injury rates (Fig. 1D) this downward trend was not evident (Table II). Match injury rates tended to decrease between 2002 and 2003, but increased again in 2004. As match injuries contributed to most injuries sustained during the season, the same pattern reflected in the overall injury rates (Table II). The lower injury rate in 2003 coincided with a sizeable reduction in in-season training volume. The medical and coaching staff then reduced the pre-season training volume in 2004, which corresponded to match and total injury rates over the season, returning to levels similar to those of 2002. It would appear that training reductions had a tendency to lower the in-season match $(p=0.06)$ and in-season total $(p=0.09)$ injury rates over the 3 years, albeit not significantly, with the most prominent reduction between 2002 and 2003. Total preseason injury rates and the number of recurrent injuries show the opposite trend, for which there were two possible reasons. Firstly, newly contracted players from other unions may have been brought into the squad with pre-existing or unrehabilitated injuries. Secondly, the rest period between the previous tournament and the start of the new season did not always allow sufficient time to rest, recover and completely rehabilitate with regard to injuries. The only major change in training between 2003 and 2004 was the reduction in pre-season training volume (Table I).

It has previously been suggested that training volume may significantly affect injury rates over a competitive season. ${ }^{11,20}$ The overall number of hours spent training during the pre-season is significantly higher than that during the in-season, ${ }^{15}$ and pre-season training contributes to approximately $38 \%$ of all training injuries. ${ }^{17} \mathrm{~A}$ previous study showed that the likelihood of injuries in rugby league increased with increasing pre-season training loads. ${ }^{20}$ However, when the authors examined the early and late competition phases in the same team, increases in training load showed no further 
increases in injury incidence. ${ }^{20}$ Another study using rugby league players showed a $10-16 \%$ reduction in pre-season training to be effective in reducing injury rates by $40-50 \%$, without compromising fitness. ${ }^{21}$ However, reductions in pre-season training may not necessarily reduce the risk of ensuing injury. ${ }^{8}$ Other research has shown that strenuous physical activity of 5 - 39 hours per week has a protective effect against injury but pre-season exposure of greater than 39 hours a week was associated with a greater risk of injury. ${ }^{9}$

During the pre-season, there are both higher training loads and a greater emphasis on tackling and defensive drills, thereby increasing contact exposure. It is therefore inevitable that injuries will result from the pre-season training. ${ }^{20}$ Although there is evidence to support reducing the pre-season training load in rugby league, ${ }^{21}$ the data from the current rugby union study question the effectiveness of reducing the pre-season training load too much. Appropriate preseason conditioning is necessary to prepare collision sport athletes for the physiological and musculoskeletal demands of competition. ${ }^{20}$ Based on the current data, it appears as if the reduction in in-season training volume alone may be more effective in lowering injury rates over a competitive season. Although not significant, the noticeable reduction in in-season match injury rates $(2002$ - 2003) and in-season total injury rates $(2002-2004)$ provides moderate support for this conclusion. Nonetheless, with the reduction in overall training load over the 3 years, there was no statistically significant improvement in either the number of injuries or the overall injury rates. In addition, it should be noted that the team studied here ended 3rd, 9th, and 7th in the Super 12 tournament during 2002, 2003 and 2004, respectively. This raises questions around the effect it may have on the overall performance of the team. The team had most injuries when they ended 3rd and least injuries when they ended 9th in the tournament. It is currently a challenge for strength and conditioning specialists to establish the optimum balance between training volume and intensity to effectively reduce injuries without compromising the necessary improvements in physical fitness and performance. ${ }^{20,21}$

\section{Training effects}

Although the incidence of injury during training is far less than during matches, one cannot negate the possible effect of rugby training as a cause of injury. ${ }^{15}$ Unlike during the match situation, one can to a large extent control what happens during training. ${ }^{17}$ Because of the physical nature of rugby, training sessions require adequate intensity to optimally develop the fitness parameters required to compete effectively. ${ }^{21}$ The effects of so-called 'match fitness' drills that encompass rugby-specific training, such as physical impact drills, have not been sufficiently researched. Game-specific drills incorporating elements of contact such as rucks and mauls have the highest risk of injury. ${ }^{15}$ Further study is required to ascertain the level and progression of match fitness conditioning necessary to adequately prepare players for rugby matches and reduce the risk of injury. ${ }^{9}$

\section{Conclusion}

This study showed that a reduction in in-season and overall training volume was associated with a slight reduction in the number of acute injuries and in-season injury rates over the three seasons. The prevention strategies, however, had minimal effect on overall match, training and total injury rates and the performance of the Super 12 rugby team as defined by their position on the log, which tended to decline. One has to be cognisant of the fine balance between performance improvement and the risk of injury when designing training programmes for elite rugby players. ${ }^{15}$ Further studies are required to determine how much training is optimal to maintain or increase rugby performance while effectively reducing injury rates. ${ }^{20,21}$

\section{REFERENCES}

1. Duthie G, Pyne D, Hooper S. Applied physiology and game analysis of rugby union. Sports Med 2003;33(13):973-991.

2. Brooks JH, Fuller CW, Kemp SP, Reddin DB. Epidemiology of injuries in English professional rugby union: part 1 match injuries. Br J Sports Med 2005;39(10):757-766.

3. Bathgate A, Best JP, Craig G, Jamieson M. A prospective study of injuries to elite Australian rugby union players. Br J Sports Med 2002;36(4):265269.

4. Silver JR. The impact of the 21st century on ruby injuries. Spinal Cord 2002;40:552-559.

5. Williams JP. Rugby union. Spinal Cord 2002;40(12):669.

6. Garraway WM, Lee AJ, Hutton SJ, Russell EB, Macleod DA. Impact of professionalism on injuries in rugby union. Br J Sports Med 2000;34(5):348351.

7. Olds T. The evolution of physique in male rugby union players in the twentieth century. J Sports Sci 2001;19(4):253.

8. Lee AJ, Garraway WM, Arneil DW. Influence of preseason training, fitness, and existing injury on subsequent rugby injury. $\mathrm{Br} \mathrm{J}$ Sports Med $2001 ; 5(6): 412-417$.

9. Quarrie KL, Alsop JC, Waller AE, Bird YN, Marshall SW, Chalmers DJ. The New Zealand rugby injury and performance project. VI. A prospective cohort study of risk factors for injury in rugby union football. $\mathrm{Br} \mathrm{J}$ Sports Med 2001; 5(3):157-166.

10. Silver JR. Professionalism and injuries in rugby union. Br J Sports Med 2001;35(2):138.

11. Millson HB, Hechter GD, Aginsky KD, Bolger C, Saunders CJ. The nature and incidence of injuries in a Currie Cup rugby team from 2001 to 2003. S Afr J Sports Med 2005;17(2):13-17.

12. Fuller CW, Molloy MG, Bagate C, et al. Consensus statement on injury definitions and data collection procedures for studies of injuries in rugby union. Clin J Sports Med 2007;17:177-181.

13. Brooks $\mathrm{JH}$, Fuller $\mathrm{CW}$. The influence of methodological issues on the results and conclusions from epidemiological studies of sports injuries. Illustrative examples. Sports Med 2006;36(6):459-472.

14. Brukner P, Khan K. Clinical Sports Medicine. Sydney: McGraw-Hill, 1994.

15. Brooks JH, Fuller CW, Kemp SP, Reddin DB. Epidemiology of injuries in English professional rugby union: part 2. Training injuries. Br J Sports Med 2005;39(10):767-775.

16. Brooks JH, Fuller CW, Kemp SP, Reddin DB. A prospective study of injuries and training amongst the England 2003 Rugby World Cup squad. $\mathrm{Br}$ J Sports Med 2005;39(5):288-293.

17. Holtzhausen LJ, Schwellnus MP, Jakoet I, Pretorius AL. The incidence and nature of injuries in South African rugby players in the rugby Super 12 competition. S Afr Med J 2006;96(12):1260-1265.

18. Best JP, Mclntosh AS, Savage TN. Rugby World Cup 2003 injury surveillance project. Br J Sports Med 2005;39(11):812-817.

19. Garraway WM, Macleod DAD. Epidemiology of rugby football injuries. Lancet 1995;345(1485):1487.

20. Gabbett TJ, Domrow N. Relationships between training load, injury, and fitness in sub-elite collision sport athletes. J Sports Sci 2007;25(13):15071519.

21. Gabbett TJ. Reductions in pre-season training loads reduce training injury rates in rugby league players. Br J Sports Med 2004;38(6):743-749. 